American Journal of Pharmaceutical Education 2018; 82 (5) Article 6603.

\title{
COMMENTARY
}

\section{Practical Tips for Integrating Clinical Relevance into Foundational Science Courses}

\author{
Jessica M. Greene, PharmD, ${ }^{a}$ Kathryn A. Fuller, PharmD, ${ }^{a}$ Adam M. Persky, PhD ${ }^{a, b}$ \\ ${ }^{a}$ UNC Eshelman School of Pharmacy, University of North Carolina at Chapel Hill, North Carolina \\ ${ }^{\mathrm{b}}$ Associate Editor, American Journal of Pharmaceutical Education, Arlington, Virginia
}

Submitted June 21, 2017; accepted October 10, 2017; published June 2018.

\begin{abstract}
The integration of foundational science and clinical science education is a hallmark of educational reform within the health professions, and an increasing number of pharmacy schools are implementing integrated curricula in professional pharmacy programs. Although the foundational sciences serve as an essential framework for understanding clinical knowledge, instructors may face challenges when integrating clinical science into foundational science courses. Here we present practical learnercentered teaching tips to address these challenges.
\end{abstract}

Keywords: curricular integration, pharmacy education, relevance, clinical sciences, basic sciences

\section{INTRODUCTION}

It has been argued that foundational science instructors "must take the initiative to relate basic science concepts to therapeutic decisions," however, these instructors may face several challenges when integrating clinical science concepts into their courses. ${ }^{1}$ Instructors may be accustomed to teaching using traditional lecture-based instruction that focuses on content delivery and places less emphasis on knowledge application and critical thinking. Most commonly, foundational science instructors are trained in basic science disciplines, resulting in a lack of clinical knowledge necessary for relating concepts to clinical practice. New instructors may also have limited formal training in pedagogy. Here we present practical tips to help new foundational science instructors integrate clinical sciences into their courses. Throughout, the manuscript, we use the term foundational science instead of basic science to discern the relationship between sciences underlying pharmacy practice versus the sciences underlying other future applications (eg, benchtop research).

Foundational science knowledge serves as an organizational framework for clinical reasoning, and pharmaceutical science knowledge underpins the clinical knowledge students learn later in professional pharmacy curricula. $^{2}$ Medical education research shows that expert and novice clinicians use foundational science knowledge extensively when diagnosing complicated "non-textbook" patient cases. ${ }^{3,4}$ Unfortunately, since students begin their training with limited clinical knowledge, they may not

Corresponding Author: Adam M. Persky, 2312 Kerr Hall, CB 7569, 301 Pharmacy Ln., UNC Eshelman School of Pharmacy, Chapel Hill, NC 27713. E-mail: apersky@unc.edu recognize the relevance or importance of foundational science concepts in therapeutic problem solving. Students may ask, "Why do I need to know this to be a pharmacist? What does this have to do with pharmacy practice?" These questions can be addressed in the first tip: make learning relevant to the goals of the student.

Like other adult learners, pharmacy students value learning experiences that are relevant to the desired outcome (ie, becoming a pharmacist). ${ }^{5}$ If students do not see the direct relevance of foundational science courses in their future careers, they may lack the motivation to engage in deep learning. Therefore, it is important to contextualize foundational science in a clinical framework so students can recognize both the importance of learning the information and its future applications during clinical training and practice.

To understand the clinical framework and context, non-clinician instructors should familiarize themselves with foundational science learning outcomes for professional Doctor of Pharmacy students. The American Association of Colleges of Pharmacy charged a task force to develop detailed, discipline-specific pharmaceutical science educational outcomes to supplement the Accreditation Council for Pharmacy Education (ACPE) Standards and the 2004 Center for the Advancement of Pharmacy Education (CAPE) Outcomes. ${ }^{6}$ The foundational science CAPE Supplemental Educational Outcomes is a good starting point for non-clinician instructors to gain familiarity with professional pharmacy scientific competencies and set the stage for developing learning objectives. ${ }^{7}$

After gaining an appreciation for the foundational science knowledge and skills required for success as 


\section{American Journal of Pharmaceutical Education 2018; 82 (5) Article 6603.}

a practicing pharmacist, the instructor should design course learning objectives focused on helping students achieve these outcomes. When developing these learning outcomes, instructors should ask themselves "In the future, how will students use this knowledge to assess a patient, create a treatment plan, evaluate patient response to therapy, or make a clinical decision? What should students know or be able to do as health care providers upon completion of the course? How will the skills and knowledge that students learn in this course prepare them for success in future courses and experiential learning?" Answers to some of these questions may require input from pharmacy practice colleagues. Learning objectives should explicitly state how students will apply foundational science knowledge in their future careers as medication experts. Table 1 lists some examples.

To facilitate the development of expertise, foundational science should be taught only to the extent that is relevant to the development of encapsulating concepts. ${ }^{8,9}$
Medical educators have spent decades studying how knowledge is organized in physicians' memory and theorizing how novice medical students develop expertise. In the knowledge encapsulation theory, basic science knowledge becomes encapsulated in diagnostic labels that explain signs and symptoms; these "illness scripts" become important for pharmacists as well. ${ }^{9}$ For a pharmacist, after a potential medication-related problem is identified, the pharmacist must assess the patient case by comparing the facts of the case to prior experiences, and then develop recommendations for an actionable plan of care. For example, a patient may walk into a community pharmacy seeking a treatment for rash. Upon questioning and reviewing the patient's medications, the pharmacist realizes the patient was prescribed sulfamethoxazole-trimethoprim and starts to think the rash may be a sign of sulfa-allergy. Development of medication-related problem "scripts" requires the pharmacist to understand foundational science knowledge,

Table 1. Examples of Traditional Learning Outcomes, Their Clinical Relevant Version and Example Learning Activity

\begin{tabular}{ll}
$\begin{array}{l}\text { Traditional Learning Outcome for } \\
\text { a Foundational Science Course }\end{array}$ & Clinically Relevant Learning Outcome \\
\hline $\begin{array}{ll}\text { Describe how functional groups affect } \\
\text { the pKa of a drug. }\end{array}$ & $\begin{array}{l}\text { Describe how we can use tissue pH to } \\
\text { change drug disposition (eg, renal } \\
\text { clearance, tissue targeting). }\end{array}$
\end{tabular}

Explain how functional groups affect small molecule solubility.

Describe the physical composition of aerosols.

Emphasize the mathematical tools needed for quantitative analysis of chemical kinetics, drug stability, and tissue drug Concentration-Time Profile.
Differentiate the absorption or dissolution You are a member of the Pharmacy and characteristics of drug molecule based on its structure/solubility characteristics.

Educate a patient on the dosage forms and drug delivery systems used to deliver drugs via the pulmonary route.

Estimate the shelf-life of a liquid dosage form.

Calculate the half-life of a drug within a patient.
Example Learning Activity

A patient is taking an antihistamine for seasonal allergies. He claims that sometimes he gets drowsier depending on what he eats throughout the day. Explain how food may impact the urinary excretion of an antihistamine.

Therapeutics Committee at a small hospital. A new hydrophilic prodrug formulation has been approved by the FDA. Your hospital currently only has a subcutaneous suspension formulation available for use. You must determine if the new product poses a significant advantage to patients to justify the costs of adding it to the formulary.

A patient asks you why her multiple inhalers all have different instructions for administration and storage. Develop a response to the patient's inquiries based on the provided medication list.

A patient with chronic kidney disease is receiving vancomycin. A random blood sample is taken right before dialysis and another sample immediately after dialysis. Calculate the half-life of vancomycin in this patient during dialysis. 


\section{American Journal of Pharmaceutical Education 2018; 82 (5) Article 6603.}

such as the structure of drug molecules, the pathophysiology of the hypersensitivity, and the pharmacology of potential ameliorating agents. To help students develop these scripts, instructors should create opportunities for students to use foundational knowledge to solve problems like those they will face in practice. This can be achieved with the next tip: use active learning strategies to help students apply their knowledge.

Once the instructor writes learning objectives at an appropriate level for novice pharmacy students, he or she should design various active learning strategies to help students construct integrated clinical and basic science knowledge. The constructivist learning theory states that students create their own understanding and knowledge of the world through experience and reflection on their experiences. ${ }^{10}$ As such, students gain experience and reflect on their experiences through active learning, which can be defined as "anything that involves students in doing things and thinking about the things they are doing."11 Research shows that active learning improves retention of information, problem solving and higher-order skills. ${ }^{12}$ Gleason and colleagues describe several active learning techniques and strategies that instructors may find useful for integrating clinical and basic science. ${ }^{13}$

Helping students apply foundational science knowledge to pharmacy practice requires time. Instructors must allow sufficient time on task for mastery of essential content, which may require the instructor to cover less nonessential content. When choosing content to include in the course, ask if the content is important to the respective field of study and if it is essential for students to make better clinical decisions. Topics that fulfill both requirements should be the focus of the course, while topics that only meet one criterion may be more suitable for elective courses. If a content is neither important nor essential for clinical decision-making, the instructor should consider removing it from the course. Since the density or amount of information taught in any one lesson impacts retention of information, it is advantageous to have lower density courses. ${ }^{14}$ Omitting a few discipline-specific, isolated topics may allow instructors to spend more time helping students apply concepts in a relevant clinical context. The time allotted for practice also depends on the complexity of the learning activities, which should increase as student become more familiar with the content and gain expertise. This leads to the next tip: scaffold the learning experience.

When designing active learning experiences, instructors should scaffold the learning experience. Building expertise requires intentionally sequencing the problem-solving process - starting with easier activities and increasing complexity and independence over time - or scaffolding. ${ }^{15}$ Early in the curriculum when students tend to take more foundational science courses, they may lack the clinical knowledge to learn independently from complex case studies. Instructors should begin with smaller, less complex learning activities like discussion of relevant patient cases and incorporation of clinical pearls. Clinical pearls are short, straightforward pieces of clinical advice that prepare students for the transition from the classroom to pharmacy practice. These pearls can function as smaller cases, allowing students to connect basic and clinical science concepts practice. ${ }^{16}$ Incorporation of clinical pearls into a basic pharmacology course has been shown to increase knowledge retention. ${ }^{17}$ Non-clinical instructors can identify clinical pearls through discussions with pharmacy practice faculty, pharmacy residents, students who completed advanced experiential learning, patient counseling points in package inserts, drug or food interaction databases such as UptoDate or LexiComp or through published patient case reports.

To avoid confusing students, learning materials at the beginning of the course should contain simple patient cases with only critical clinical information. Instructors may choose to include additional background details (eg, history of present illness, social history) to motivate students by making a case more interesting. In these situations, it may be helpful to exclude some of the details from the written case or slide but verbally state the interesting details. This method has been shown to reduce the distraction of the non-essential material. ${ }^{18}$ A simplified clinical context also helps students focus on the important points of the case. Simplifying problem-solving activities (eg, reducing extraneous case details and providing guiding questions) helps instructors control the focus of case discussion and identify misconceptions about applying course material. Once the instructor has corrected student misconceptions, and students have practiced thinking about foundational science in a simplified clinical context, students will be better equipped to solve case-based problems independently. After students have a sufficient introduction to how foundational science is applied in practice, instructors should consider introducing more complex, higher-level, independent learning activities, such as case-based learning (CBL), which allow students to apply their knowledge to real-world scenarios and increase engagement and motivation. ${ }^{17,19-21}$ The next tip deals with how to generate these clinical cases or vignettes.

Creating materials for clinically relevant CBL can be time consuming and challenging for non-clinician scientists who lack access to real patient information or practice expertise. First, instructors may find it helpful to adapt simple patient cases from clinical reference books 


\section{American Journal of Pharmaceutical Education 2018; 82 (5) Article 6603.}

or published case reports, and then develop guiding questions to help students focus on the fundamental scientific principles of the clinical case. Another potential solution is to give learners the opportunity to research real-world cases. Students become curious and motivated if they are given the opportunity to investigate a problem that appeals to their interest. ${ }^{22}$ To promote inquiry, instructors should consider assigning activities that provide opportunities for students to research topics that appeal to their curiosity (eg, rare disease states, clinical controversies, new drugs with first-in-class mechanisms, novel drug delivery platforms, etc.). Exploration activities that have worked well in our experiences include sharing "realworld" examples from the news in an online forum, student interviews with clinicians, and student development of clinical cases. Student-created clinical cases can be refined for use in subsequent class sessions or courses.

Another approach for finding clinically relevant materials is sharing or integrating patient case vignettes across multiple courses. Sharing cases in both foundational science and clinical science courses may promote knowledge transfer across contexts. Learning in a single context limits transfer of knowledge. ${ }^{23}$ When students view a patient from a multidisciplinary perspective, they can understand how foundational science and clinical knowledge integration are essential for optimal patient care. The next tips focus on strategies to help students build a multidisciplinary perspective to patient care.

To help students view patient care from a multidisciplinary perspective, foundational science instructors should consider inviting clinical faculty to either co-develop or co-teach foundational science courses. ${ }^{24}$ Since foundational science and clinical faculty have different opinions on the depth of biomedical knowledge necessary for clinical practice, ${ }^{25}$ collaborative course development and teaching efforts may provide better insight and consensus on this matter. For example, clinical faculty can facilitate decisions on what course content is essential for practitioners, assist with development of practical learning activities that reflect real-world scenarios, and model the critical thinking process to show students how they will use their basic science knowledge in the future. Conversely, basic scientists can provide clinicians with the fresh perspective of investigational treatment strategies that likely will be clinically relevant whenever students enter practice. For foundational science content to be learned and retained, foundational science courses need to help students apply concepts in clinical scenarios, and clinical courses need to review underlying foundational science concepts. This may require longitudinal conversations between the clinical and foundational science faculty.

While there are challenges to attaining sufficient interaction between clinical and foundational science faculty, these barriers can be addressed and overcomed. ${ }^{26}$ At the institutional level, curriculum and course developers should consider partnering faculty members from different departments to design integrated learning materials and activities. It also may be helpful for clinical faculty to visit research laboratories and for foundational science faculty to shadow a clinician in a practice setting. Another idea is to implement collaborative quality improvement programs, involving teams of both pharmaceutical science and practice-based faculty members, to promote collegiality and improve curricular design. One such quality improvement program is peer review of course materials (eg, clinical cases, learning activities, assessments). During the peer review process, correspondence between instructors leads to the identification of errors in teaching materials and reduction of unintended content overlap across courses. ${ }^{27}$ Foundational science and clinical faculty within the same program are likely to value peer

Table 2. Practical Tips for Integrating Clinical Sciences into Foundational Science Courses

Align course learning outcomes with basic science competencies for pharmacists (eg, CAPE Supplemental Educational

Outcomes).

Contextualize foundational science content in a clinical framework and illustrate clinical relevance through learning objectives. Avoid teaching dense, discipline-specific basic science content.

Avoid using the same teaching materials for both graduate students and professional students.

Provide opportunities for students to construct integrated basic and clinical science knowledge through active learning.

Scaffold the learning experience by increasing the complexity of learning activities over time.

Model critical thinking and problem-solving before asking students to do it independently.

Use case reports or commercial case study books to work backwards and design clinically relevant foundational science questions. Provide opportunities for students to research real-world examples of how basic science relates to pharmacy practice.

Share clinical cases and learning activities across multiple basic and clinical science courses to facilitate transfer of learning. Promote curricular integration by partnering basic science faculty with clinical faculty to develop and review course materials. 


\section{American Journal of Pharmaceutical Education 2018; 82 (5) Article 6603.}

review of each other's materials in both course and curricular planning. Foundational science instructors can learn more about how their content relates to subsequent courses, and clinical instructors who teach later in the curriculum can use this process to inform vertical curricular integration.

Most of these tips thus far focus on making foundational courses more clinically relevant. Each lesson in the early years of the curriculum should emphasize how understanding foundational science improves patient care. However, to fully reinforce the foundational knowledge, pharmacotherapy courses should reinforce major foundational science concepts. Clinical faculty and preceptors can review content by asking the following questions: What is the basic underlying pathophysiology of this disease state? Why does a drug preferentially penetrate certain tissues? How does the side effect profile relate to off-target drug pharmacology? The curriculum is a roadmap for learning, and learning requires deliberate practice and intentional, scaffolded repetition. Foundational science content can be integrated into the clinical decisionmaking process only if all instructors share the same vision and collaboratively design the curriculum content and sequence.

\section{CONCLUSION}

Teaching within an integrated pharmacy school curricula can present unique challenges for non-clinician foundational science instructors. Major challenges include determining the breadth and depth of foundational science content for future pharmacists, implementing active learning strategies to help students think of basic science in a clinical context, developing clinically relevant course materials, and collaborating with clinical faculty colleagues. The above discussion presents guidance for foundational science instructors to overcome these obstacles when designing courses in integrated curricula, and practical tips are summarized in Table 2. While individual instructors work diligently to incorporate evidence-based teaching strategies in their classrooms, administrators should also reflect on their procedures for curriculum development. Pharmacy schools must optimize curricular planning to promote collaborative teaching practices across divisions and departments to ensure teaching quality and continuity from bench-top researchers to bedside clinicians.

\section{ACKNOWLEDGMENTS}

The authors would like to thank Kayley Lyons, Tom Angelo, and Mike Jay for their thoughtful review of the manuscript. Kathryn Fuller is currently a post-graduate year 1 resident at UNC Medical Center.

\section{REFERENCES}

1. Harrold MW. Educational challenges facing basic science faculties. Am J Pharm Educ. 2004;68(1):Article 15.

2. Kulasegaram K, Manzone JC, Ku C, Skye A, Wadey V, Woods NN. Cause and effect: testing a mechanism and method for the cognitive integration of basic science. Acad Med. 2015;90(11 Suppl): S63-S90.

3. Norman GR, Trott AD, Brooks LR, Smith EKM. Cognitive differences in clinical reasoning related to postgraduate training. Teach Learn Med. 1994;6(2):114-120.

4. Woods NN, Brooks LR, Norman GR. The role of biomedical knowledge in diagnosis of difficult clinical cases. Adv Health Sci Educ Theory Pract. 2007;12(4):417.

5. Sogunro OA. Motivating factors for adult learners in higher education. Int J High Educ. 2014;4(1):22-37.

6. American Association of Colleges of Pharmacy. 2004 CAPE supplemental educational outcomes. https://www.aacp.org/sites/ default/files/2017-11/Combined-CAPE-2004-Supplemential-

Educational-Outcomes.pdf. Accessed June 9, 2017.

7. Nazarian A, Bloom T, Oliveira M, et al. CAPE 2013 supplemental educational outcomes for biological sciences, chemistry, and pharmaceutics. 2014.

8. Schmidt HG, Rikers RM. How expertise develops in medicine: knowledge encapsulation and illness script formation. Med Educ. 2007;41(12):1133-1139.

9. Persky AM, Robinson JD. Moving from novice to expertise and its implications for instruction. Am J Pharm Educ. 2017;81(9):Article 6065 .

10. Biggs J. Enhancing teaching through constructive alignment. Higher Educ. 1996;32(3):347-364.

11. Bonwell C, Eison J. Active learning: creating excitement in the classroom. 1991 ASHE-ERIC higher education reports.

12. Prince M. Does active learning work? A review of the research. $J$ Engineer Educ. 2004;93(3):223-231.

13. Gleason BL, Peeters MJ, Resman-Targoff BH, et al. An activelearning strategies primer for achieving ability-based educational outcomes. Am J Pharm Educ. 2011;75(9):Article 186.

14. Russell IJ, Hendricson WD, Herbert RJ. Effects of lecture information density on medical student achievement. Acad Med. 1984;59(11):881-889.

15. Collins A, Brown JS, Holum A. Cognitive apprenticeship: making thinking visible. Am Educ. 1991;15(3):6-11.

16. Lorin MI, Palazzi DL, Turner TL, Ward MA. What is a clinical pearl and what is its role in medical education? Med Teach. 2008;30(9-10):870-874.

17. Persky AM, Wells MA, Sanders KA, Fiordalisi J, Downey C, Anksorus HA. Improving dental students' long-term retention of pharmacy knowledge with "medication minutes." J Dental Educ. 2017;81(9):1077-1084.

18. Yue CL, Bjork EL. Using selective redundancy to eliminate the seductive details effect. Appl Cogn Psych. 2017;31(5):565-571.

19. Popil I. Promotion of critical thinking by using case studies as teaching method. Nurse Educ Today. 2011;31(2):204-207.

20. Thistlethwaite JE, Davies D, Ekeocha S, et al. The effectiveness of case-based learning in health professional education. A BEME systematic review: BEME Guide No. 23. Med Teach.

2012;34(6):e421-e44. 


\section{American Journal of Pharmaceutical Education 2018; 82 (5) Article 6603.}

21. Malau-Aduli BS, Lee AY, Cooling N, Catchpole M, Jose M, Turner R. Retention of knowledge and perceived relevance of basic sciences in an integrated case-based learning (CBL) curriculum. BMC Med Educ. 2013;13(1):139.

22. Keller JM. Motivational Design for Learning and Performance: The ARCS Model Approach. New York, NY: Springer Science \& Business Media; 2009.

23. Collard A, Brédart S, Bourguignon J-P. Context impact of clinical scenario on knowledge transfer and reasoning capacity in a medical problem-based learning curriculum. Higher Educ Res Dev. 2016;35(2):242-253.
24. Schmidt $\mathrm{H}$. Integrating the teaching of basic sciences, clinical sciences, and biopsychosocial issues. Acad Med. 1998;73(9 Suppl): S24-S31.

25. Koens F, Custers EJ, Ten Cate OT. Clinical and basic science teachers' opinions about the required depth of biomedical knowledge for medical students. Med Teach. 2006;28(3):234-238.

26. Islam MA, Talukder RM, Taheri R, Blanchard N. Integration of basic and clinical science courses in US PharmD programs. Am J Pharm Educ. 2016;80(10):Article 166.

27. Cowen DL, Davis GL, Bird SE. Peer review in medical education. Acad Med. 1976;51(2):130-131. 